\title{
Vulnerable writing as a feminist methodological practice
}

\author{
Tiffany Page, Goldsmiths, University of London
}

\begin{abstract}
This article discusses the possibility for vulnerable writing within feminist methodological approaches to research. Through drawing upon a project that involved difficulties and tensions in conducting transnational research, including the documenting and telling a partial narrative of an individual who set herself on fire, the article discusses what it might mean to more explicitly focus on explicating and recognising vulnerability in writing. In providing examples from working with a situated, localised analysis that engages feminist, postcolonial and queer theoretical approaches to attend to the particular and everyday, I address some of the hesitations and uncertainties in undertaking research and producing knowledge, and concerns with forms of reflexive practice. At the heart of the discussion is the question of a vulnerable ethics, of how it is possible for feminist methods to represent the lives of others, especially when stories fail in the telling, both in providing adequate explanations, and in the ways that trauma and suffering can remain incommunicable. Included in this are concerns as to how we as researchers are affected within the production of research. As a form of receptivity and wounding, the article argues for vulnerable writing that challenges feminist methods to remain open and receptive to what will always resist sense-making, while continuing to respond to the demand that we do justice to the lives of others.
\end{abstract}

\section{Key words}

Vulnerability, transnational, ethics, methodology, uncertainty, time

\section{Introduction}

I begin with a narrative of an incident that occurred in Lebanon during the morning of 25 March 2014. Mariam al-Khawli, a Syrian woman who fled her country after the outbreak of civil war and arrived in Lebanon with her husband and four children in early 2012, stood outside the United Nations Refugee Agency (UNHCR) office in Tripoli. While Khawli's family had received food assistance in the form of vouchers from the World Food Programme since registering as refugees upon their arrival in Tripoli, some time in August 2013 her family was deemed to be no longer eligible for aid. The food assistance was not reinstated despite Khawli's frequent visits to the UN offices, which included her trip on 25 March. That morning, Khawli took out a small plastic bottle from her bag and poured its contents of diesel over her head and clothes and set herself on fire in front of the building and others queuing that day. Bystanders and UN guards attempted to smother the flames with their coats and with water. Khawli was taken to Al-Salam Hospital with third degree and deep second degree burns. Khawli survived and was interviewed by global media networks and recorded on video while lying in bed in her hospital room. Around a month after setting herself on fire, Khawli died as a result of her burns. While her self-immolation created global attention, there was no reporting of Khawli's death by the global media. 
Khawli's story is influenced by and grounded within specific political unrest and violence with its own complex history and context, which created the need for Khawli to flee one deeply precarious space for another. Her story occurs in the context of the 4.84 million who had left Syria by early June 2016 and registered with the United Nations Refugee Agency (UNHCR). ${ }^{1}$ The story of Khawli's self-immolation therefore is also a story of how we encounter, welcome, host and turn away strangers. It raises ethical questions of hospitality and our receptiveness to others, and the conditions we place upon the arrival or proximity of those unfamiliar to us (Dikeç et al. 2009; Ahmed 2000; Derrida 2000). In providing my engagement with Khawli's story as an example of my own vulnerable encounter with feminist, postcolonial and queer research methods, I suggest that textual and methodological strategies that approach the translation and narration of accounts and stories about the lives of others, without permission or consent, are inherently vulnerable. Responses to the emotions involved in research and the ways of working with and being worked on by stories have implications for how textual analysis is conducted and more broadly for feminist methodological approaches to research. In this article I want to address particular ways of writing vulnerably that might help to bring certain forms of knowing and unknowing into focus.

I use the term 'vulnerable writing' to describe the process of explicating and recognising vulnerability in writing. While all research involves aspects of vulnerability and forms of notknowing, I put forward the notion of vulnerable writing as a means in which to engage specifically in recognising this aspect within the research process. I propose that modalities of not-knowing within the production of knowledge are pertinent especially within transnational research. As well as exposing the fragility of knowledge assembly, a vulnerable methodology might be closely positioned with questioning what is known, and what might come from an opening in not knowing. This involves questions of ethics: the ethics involved in modes of telling, the sensory and affective responses to the material production of research, and the forms of violence committed in narrating the stories of vulnerable others. Specifically in this article, I question how a vulnerable methodology might help to interrogate the ways that knowing ahead of time can become commensurable with ethical action, and the temporal relation between ethics and epistemology. Therefore, what is at the heart of vulnerable methods and writing are ongoing questions about what unsettles and relations to the unfamiliar and strange, and how this might start to be addressed through the slow examination of the varying and multi-layered modalities of vulnerability involved in research practices.

The story of Mariam al-Khawli was one of two accounts of individuals who set fire to their own bodies, or what is commonly referred to as self-immolation, included in my PhD research on vulnerability. The transnational research that I undertook centred on developing partial narratives on the life of Khawli and one other individual who, in different countries and under different circumstances, set themselves on fire. Developing the narratives became one means of tracing the complex and contested understandings of what vulnerability is, and what it does. Its varying registers, including its presence within

\footnotetext{
${ }^{1}$ Source: Syrian Regional Refugee Response Inter-Agency Sharing Portal. Figures last updated 2 June 2016. Available at: http://data.unhcr.org/syrianrefugees/regional.php\# [Last accessed 19 June 2016].
} 
structural, ontological, and affective dimensions of experience, were brought into sharp focus through the story of Khawli. I came to write about self-immolation, and specifically the story of Khawli, due to what I perceived to be the political ambivalence of the act. While bearing connection to the struggles that Judith Butler describes more recently in the context of political assemblies that involve bodies acting in concert to demand the end to 'unwilled conditions of bodily exposure' and when 'sometimes deliberately exposing the body to possible harm is part of the very meaning of political resistance', I was uncertain if this could include self-immolation (2015: 126). As a means of bodily exposure that often ends in death, I was uncertain as to whether the setting fire to one's own body could be understood unequivocally as a public act of resistance, or a private act of suicide, or whether its ambiguity was something I could not resolve.

My engagement with feminist methodological strategies in this project specifically involved working with intersecting feminist, postcolonial and queer critiques and approaches that, in the context of Khawli's story, began to call attention to the ways in which erasures can occur to the specificities of subjects and their particular bodies. Documenting a narrative that focused on Khawli's life became grounded within a concern for ethics and especially the violence committed in narrating the stories of vulnerable others. I was conscious of the distance presented by own subject position as a Pakeha (white) New Zealander based in the UK and what this meant for me assuming a role as an (unchosen) narrator telling the story of Khawli without her permission or the consent of her family members.

There are further methodological fragilities in the tensions involved in conceptualising vulnerability as a shared, existential condition that is a feature of living beings exposed to harm and the risk of injury and death, and the conditionality of that exposure that I suggest might engage particular qualities or elements of vulnerability. I was conscious of placing a theoretical framework that has emerged predominately from North America and Western Europe, with its lineage often traced post 9-11 to the work of Butler $(2004,2009,2015)$, in conversation with a particular practice of self-harm that occurs rarely, and predominantly under conditions of extreme precarity in specific geopolitical locations in Asia and the Middle East (Ahmadi et al. 2014; Aziz 2011). One of the ways I came to address some of these theoretical and ethical concerns was to shift the focus of vulnerability to the ways it has been addressed in feminist postcolonial scholarship. As well as my concerns as to the conceptualisation of vulnerability, it is important to address that self-immolation has its own contextual insecurities. In naming the action of setting one's body on fire, self-immolation comes to define the self-immolator through particular spatial relations, by attempting to predict a person's intentions, read as responses to one's environment, as being either political (protest) or personal (suicide) according to the location in which the self-immolation occurs, and whose body it is that is burnt.

I set this scene of unsettled and unstable epistemological ground because my engagement with modes of narrative involving Khawli's life and her self-immolation came to be defined by ambivalence, discordance and uncertainty both within the account and in how Khawli's actions were interpreted by global media. The growing hesitations I felt in pursuing this research exposed the vulnerabilities of the project and my own escalating uncertainty over 
how an act of self-harm involving an extreme form of violence could be narrated without enacting forms of epistemic and symbolic violence through the representation of Khawli's life and her self-immolation. My need and desire to produce knowledge from a person's experience of suffering was a tension that I held with me throughout the research. There are forms of violence involved in the burden placed upon others to share or allow to their stories be told, for stories to be used for particular purposes with and without permission, and in the demands for intelligibility within modes of telling. It was through modes of vulnerable writing that I began to consider how it might be possible instead to shift the focus from an acute moment in time to the layers of stories that come to be transposed unevenly across different bodies and within different locations and conditions. I did this through making a decision to attend to ordinary, everyday modes of self-maintenance and endurance required to sustain lives.

Initially Khawli became a problem of intention that I thought I could solve. Khawli stood outside the UN office and lit her body on fire, and spoke after this event. My initial readings of her story and the epistemic claims that I made as to her subjectivity and agency, demarcated Khawli's attachments, sensibilities and dependencies to the life she inhabited as being able to be accessed. While the burning of one's body is a form of and response to extreme trauma, which may resist being made intelligible to those outside of such an experience, within the research process self-immolation can become transformed and understood within existing frames of hermeneutic and analytic knowledge. Saba Mahmood directly addresses feminist projects of cross-cultural translation, where a method of rendering the other through hegemonic discourses commits epistemic violence 'when it tries 'to assimilate the Other to a language of translatability' (2012: 199). Mahmood argues that through this process of translation, unfamiliar, inexplicable lifeworlds are rendered into certain 'conceptual or communicable' forms, thereby taming and controlling 'that which exceeds hegemonic protocols of intelligibility' (ibid.: 199). This forces the unintelligible into a normative temporal frame where timing becomes synonymous with intention; and knowledge is produced in advance of time.

A core concern in thinking about feminist methodologies therefore is how, as feminist researchers, we might respond to others in ways that allow for the acknowledgement of vulnerability in being faced by that which exceeds knowledge, to remain open to alternatives through enabling the space and time to question assumptions and forms of certitude, to return to materials, and to change our minds. This form of vulnerable writing, where figuring through how receptivity to not knowing, to remaining with uncertainty and hesitancy can become integral to particular textual strategies and methodological approaches, became something I continued to tussle with through the life of the project. These concerns reflect similar ethical questions posed by Mahmood that I have adapted here and will engage with in this article: What kinds of relations are formed with the subjects of research? What might it mean not to fully comprehend the lives upon which we make epistemic claims (ibid.: 198)? And what are the kinds of feminist analytic and hermeneutic resources that can help in thinking through such ethical concerns (ibid.: 195)?

\section{Challenges to the time of knowledge}


In order to begin to address these questions through the disruption and reframing of approaches to knowledge I will first examine the temporal as a conditioning agent of knowledge and how this might identify one particular intersection within feminist, postcolonial and queer concerns with epistemic claims. In acknowledging the methodological lineage of feminist and queer scholarship stemming from Eve Kosofsky Sedgwick's critique of paranoid reading, Robyn Wiegman argues that Sedgwick questions the relation between epistemology and politics, where 'knowing is the means for knowing what to do' (original italics) (2014: 7). In response to the need to comprehend ahead of time, Sedgwick asks critically, 'What does knowledge do - the pursuit of it, the having and exposing of it, the receiving again of knowledge of what one already knows?' (original italics) (2003: 124). I suggest this can present a challenge to feminist research but also provide a means of re-situating projects through particular methods of reflexivity that critically question the hold that certain forms of knowledge have on our own sense of self. Mahmood addresses her own concerns with the temporal fraying of epistemological certitude. She acknowledges that the transnational approach initially employed in her study of the women's mosque movement in Egypt involved solving ahead of time what was incompatible with and incommensurable to her own feminist interests. Mahmood realised reflexively that she did this by having 'a sense of foreknowledge of what I was going to encounter, of how I was going to explain these women's 'intransigent behavior' in regard to the ideals of freedom, equality, and autonomy that I myself have held so dear' (ibid.: 198). Mahmood began to interrogate how this form of knowing, which, despite the certainty that the feeling of being ahead of time initially gave her, came to be incompatible with the 'sentiments, commitments, and sensibilities that ground these women's existence' (ibid.: 198). Through Mahmood's experience, it is possible to consider that what might be at the heart of becoming vulnerable to forms of ambivalence is the difficult task of resisting trying to eliminate or at least quell the disquiet that comes from 'the uncertain, at times opaque, conditions of intimate and uncomfortable encounters in all their eventuality' (ibid.: 198). Mahmood argues that such a mode of unsettled encountering requires that any move towards comprehending different lifeworlds first requires dislocating the certitude of one's own epistemological projections (ibid.: 199).

In tracing her own work on interrogating queer temporal asynchronies back to Sedgwick, Elizabeth Freeman argues that the privileging of future focused temporality within certain queer approaches, which insists on the disruption and disintegration of particular identities and social worlds through confining them to history, suggests that 'it's about having the problem solved ahead of time, about feeling more evolved than one's context' (2010: xiii). Freeman's notion of 'temporal drag' is helpful in this respect in its disruption of movements of time across methodological and practical concerns. Engagement with non-linear forms of temporality is also a feature in the scholarship of Jack Halberstam (2011), Heather Love (2009), and José Esteban Muñoz (2009). As a method of displacement, Freeman's engagement with 'queer time' involves researching 'against dominant arrangements of time and history' through interrogating the organisation of activities, scenes and events into consequential sequences (2010: xi). Therefore an alternative method of working with, and being worked on by time is to slowly unstitch narratives through considering 'nonsequential 
forms of time' (ibid.: xi). Freeman's analysis emerges in the context of queer performativity, where temporal drag creates conflict and incongruity within queer bodies through the tautness produced in the pull backwards from identifying with 'historical' generations and terminology, and the pushing forwards to construct new social and political movements. Freeman focuses her attention on the backwards motion, reframing it not as a means of regression but instead as an essential component within the complexity of forces and energy needed for modes of living. The 'tug backwards', in contrast to a desire to cast aside the past, can be a 'potentially transformative part of the movement' (ibid.: 93).

For example, attending to what tugged backwards within narratives can begin to illuminate how bodies, relations and attachments continue to engage in the struggle to 'endure the effort it takes to strive to persevere' within the material conditions of precarity (Povinelli 2011: 9). Rethinking agency as Mahmood (2012) does as a capacity that involves struggle, effort and exertion, can help to open up new ways to consider how time impacts upon the activities involved in sustaining life. This approach became important in the context of the story of Khawli, where it meant that instead of attending to activities that may or may not have signaled an impending decision by Khawli to burn herself, as if that was the purpose of telling her story, I focused on how Khawli might have engaged in other forms of survival, and the everyday activities of self-maintenance that occurred within her lifeworld. When I began to do this, small details began to expand the narrative. Khawli and her family ran a vegetable trading company and owned the building they lived within in Homs, Syria. During the 2012 attack on Homs, parts of their house were demolished and Khawli and her family hid overnight as shells hit the building. Khawli survived her neighbourhood being attacked and kept her children safe in the bathroom of their home. Khawli fled from Syria when her children's lives were at risk, and she refused to send her to children to work or allow her daughters to live in a communal housing situation that she deemed to be unsafe. Khawli taught her children ancient Arabic before they started school and she continued to walk the three-hour round journey from her home in Tripoli to the UNHCR offices to press her case. These details became part of the fabric of her story, enabling me to remain for longer and not lose sight of the fact that Khawli was a person attempting to persist and create new lives for herself and her family in a country that was not her own. Therefore, the notion of the backwards sweep became a method in which to probe the generative potential of epistemological uncertainties within modes of telling, where the story remains open, incomplete, and discordant in its layers. I suggest it can help to make visible the discontinuities and instabilities of narratives that change meaning when approached at varying tempos, when the story is moved not only forwards but backwards, and slowed and quickened within each space.

\section{Localised analyses of the particular}

Being vulnerable within research places unexpected affective and sensorial demands upon researchers in representing the lives of others, and involves being receptive to the limits of knowing. How do feminist researchers, through the methods we employ, become and remain open to responding to what is not understood, to what unsettles existing knowledge, and to that which cannot be explained easily through causal relations and claiming to know 
another person's intention? How, as feminist researchers, do we become attuned to others but also remain hesitant as to how and why we are moved affectively? And what if we do not know how to respond? These are questions that are not easily addressed, especially in the context of neo-liberal higher education policies and quantitative research outputs, and of the need to say and declare something. In the context of the complexities in undertaking intercultural palliative care work, Yasmin Gunaratnam addresses these tensions in the vulnerability of the encounter, and how finding yourself in a position of 'not knowing what to do or say' stands in 'sharp contrast to the securities of practice promised by the abstract systems of cultural competence' (2008: 34). Here the simultaneous and yet asynchronous existence of responsibility to another person and the 'inadequacy' of responses due to failures in comprehension unsettles any move towards closure through solving the problem or meeting a person's need (ibid.: 35). As a way of moving forward, Gunaratnam raises the question of needing to distinguish between knowledge as always being a means of knowing how and the potential of knowledge as a falling short, which can occur through the receptivity and openness that emerges from the vulnerability of 'not knowing in advance' how to respond to the 'unpredictable demands' of those unfamiliar to us (2011: 106).

This notion of remaining receptive to what cannot be known has been addressed within feminist postcolonial methodological practices. Chandra Talpade Mohanty's (1984) influential article 'Under Western Eyes: Feminist Scholarship and Colonial Discourses' continues to issue its challenge to feminist transnational research originating in North America and Western Europe to address how such work may inhabit and lay claim to the epistemology and experiences of those who are subjects within the research. Mohanty argues that such imperialist projects construct an 'essentially truncated life' of cultural others, where no such reductionism occurs within the self-presentation of particular groups who are privileged as being the 'norm or referent' (ibid.: 337). These authorial subjects engage in temporal modes of analysis that confer the status of being ahead of time, of always knowing more. Research is conducted on 'already constituted groups', connected by a singular notion of oppression or powerlessness which is enmeshed within the discursive meanings of assigned categories (ibid.: 340). In turn this leads to particular women being represented through forms of 'cultural coherence' that erase specificities and discordant elements of subjectivity (ibid.: 350 ). In a similar way, Gayatri Chakravorty Spivak calls attention to the failings of Eurocentric research within the politics of cross-cultural translation that pays insufficient care to the 'rhetoricity of the original' by not investing in understanding the complexities and layered meanings of particular sites and contexts (1993: 181).

To address the risks of feminist research operating as colonial sites that flatten and erase forms of experience, specificities, contradictions and discordant subjectivities, or restates them in ways to articulate commensurability with familiar practices, Mohanty argues for methodological responsiveness to the local and particular within research through being 'attentive to the micropolitics of context, subjectivity, and struggle, as well as to the macropolitics of global economic and political systems and processes' (2003: 501). To be centred in the local means methodological strategies need to be undergird by 'grounded, particularized analyses linked with larger, even global, economic and political frameworks' 
(ibid.: 501). Research centred on the intricacies and complexities of individual, localised or situated contexts has the potential to 'generate theoretical categories from within the situation and context being analyzed' (original italics) (1984: 345). I suggest that this space of being within is also a space of vulnerability, where it is not necessarily possible, nor the intended outcome of such methodological practices, to predict in advance how and in what directions the research will progress.

In thinking about how my own methodological approach to research became influenced by feminist postcolonial critique, as well as varying the temporal registers of Khawli's story I used Mohanty's framework of localised analysis to alter the levels in which I was accessing the narrative, moving between the micro level of everyday experiences and the macro level of the national and global systems, policies, infrastructure and institutions that might have informed the lives of those seeking refuge in Lebanon. In addressing the macro layers of the narrative, I did not want to suggest that Khawli's self-immolation could be told as a linear story, or reduced to an easy, untroubled relation of cause and effect. As Butler argues, the vulnerability established under conditions of precarity is always particular; it includes our specific dependencies and attachments to particular environments, resources, and support (2015b). Butler suggests that while conditions of precarity are mediated through the political, geographical and historical sites in which they occur, and movements of social justice seek their abolishment, vulnerability has at its essence, durability (2015b). Examining the vulnerability of Khawli therefore was one method of situating her story within the acute violence and impact of civil war, political unrest and poverty, through grounding the narrative within complex modes of endurance and what it means to keep holding on.

However, there are also risks in addressing the macro layers and in decisions as to how the micro and macro are placed in relation to each other. I suggest this is a key consideration within vulnerable methods. Khawli's self-immolation could be reduced to being understood as a particular, catastrophic micro level effect or the response to an un-interrogated macro cause. Linda Tuhiwai Smith (1999) criticises the unexamined temporal flow of forms of privileged knowing that move from localised, individual experience, to knowledge generated at the macro level and then back to becoming a resource to determine and solve issues. In considering the tension between the differences in how knowledge is gained, held and utilised within Māori society and the aims and methods of non-Māori research practices, Smith describes a form of 'crisis research' conducted by non-Māori tasked with 'explaining causes' and 'solving Māori problems' (ibid.: 174). On the basis of research conducted at particular sites, which may or may not generate understanding, 'huge inferential leaps and generalizations about how the rest of Maori society functioned' are frequently made (ibid.: 174). In a similar way Patti Lather contends that there needs to be 'recognition that we often do not know what we are seeing, how much we are missing, what we are not understanding, or even how to locate those lacks' (1999, p. 217). Both Smith and Lather's work reflect concerns with research that fails to address its gaps and absences in knowing what is inside and outside of its field of vision.

In the context of my own research project, as I continued to develop a partial narrative of aspects of Khawli's life through attending more closely and slowly to textual and material 
layers and context, the less certain I was in ascribing forms of intentionality, of being able to tell an account of how it was. I began to reflect on what I was demanding from the life of Khawli, of how forms of knowledge making are not by necessity emancipatory, and that my knowing why Khawli had decided to set herself on fire did not change anything at all. To address my uncertainty and hesitation, and as a method of attending to Smith's concerns, I placed the micro and the macro beside each other within the narrative, without suggesting that there was a necessary causal relation that could account for all of Khawli's decisions, or could have predicted how Khawli chose to act. I did this to resist a translation from the micro to the macro that assumed decisions made about self-immolation can be somehow be presented within intelligible forms and known in advance. Through placing the layers in parallel rather than upon one another to find causal connections, the tempo of lives and what impacts on them can be altered. I argue that it is not necessary that events that have closest temporal proximity or express an acute moment in time are those that may cause people to act in particular ways. I began to recognise that some deaths that we think occur quickly may instead be slow and are eked out not over minutes but rather over months, years, and generations. Therefore, I propose that feminist textual analyses involving nonsequential forms of time and that caution against the epistemic pull of relational elements between macro and micro level events can be a means of attempting to disrupt erasures performed by linear narratives striving for coherence. Instead, the discordant elements of narratives and subjectivity that point to the instability at times of relational elements remain in focus, without being resolved by tracing a linear cause and effect back to a particular localised source (Harrison 2007).

In conducting a textual analysis that involved attending to different temporalities and the parallel layering of elements within the narrative, what came into focus was the omission of Khawli being centred within her own agential and sensory experiences. Instead the complexity, materiality and temporality of suffering experienced within a long, drawn out unspectacular time of precarity was being effaced through the singular, spectacular temporal moment of self-immolation. This meant that the allure of the arresting time of self-immolation, which through its ability to capture attention conveyed the power to signify itself as the narrative endpoint, was erasing the rich textures of agential capacities that move through time and continue after a body is lit. For example, in working with the micro layers within a textual analysis, what might be opened up by addressing the material detail of the pain of setting fire to your body, and the physical and affective experience of burning? Lata Mani addresses the erasure of women's agency in pain in her analysis of the representations of sati - widow burning - in India and how the debate was primarily shaped by a colonial discourse (1998: 1). In connection to Mohanty's (1984) argument on how colonisation as a means of gendered and racialised oppression suppresses the heterogeneity of certain subjects, Mani argues that women who burned on the funeral pyre were 'neither subjects or even the primary objects of concern in the debate on its prohibition' (1998: 2). As a way of working with the materiality of affective and sensory experiences that remain hidden from view, Mani's analysis led me to consult medical articles written on burn patients to try and understand, even in some arbitrary way, how much pain is registered and endured when a body suffers full thickness burns. In working at the temporal layers of the narrative I accessed articles focusing on the treatment available in minimising pain and 
aiding recovery from wounds to find out how much Khawli might have suffered after selfimmolating. In the media articles reporting on the incident, the pain experienced remained largely absent from the framing of self-immolation. When it was present, the materiality of suffering was connected to defined temporal boundaries. Khawli experienced forms of pain and trauma only prior to her act of setting herself on fire. There is little mention in any media report, even those at her bedside in hospital, of the pain and discomfort of her burns.

Examining the layers in Khawli's life also leads to the question as to whether certain kinds of bodies are needed to perform certain actions. Khawli's husband Ahmad has a life threatening health condition that prevented him from working. I began to map out the journey that needed to be taken to the UN office, and what might be required to sustain such a journey, both physically and mentally. Was it significant that it was Khawli and not her husband Ahmad who responded to their family's desperation? As a feminist researcher based in the United Kingdom, what claims could I make about gender and self-immolation? What can erase the asking of such questions, and instead cement one's own right to knowledge, are the ways that forms of cohesiveness can become adhered to vulnerable bodies. For example, Mohanty draws attention to problems in using notions of gender as a coherent category of analysis in feminist scholarship, because this assumes 'an ahistorical, universal unity' that ignores in particular how women are constituted through a 'complex interaction between class, culture, religion and other ideological institutions and frameworks' (1984: 344). Is self-immolation something that requires a certain kind of body to perform it? How would it be possible to examine this without working at the located intersections of gender, race, religion, and cultural histories (Mahmood 2012)? What can be traced is that Khawli's self-immolation required endurance, a one and a half hour walk each way, standing in line, waiting, shielding herself from the elements of the weather, and pressing her family's case to officers within the UN office. It was a journey Khawli took at times with her husband. It also meant returning home to their children: "What can you tell them?"..."What would that do to you?"2 These actions were repeated and repeated. The endurance interwoven into the forms of time involved is compounded by environmental, social, cultural, historical and economic conditions in which such recursive activities occur.

This temporal tactic of returning to the materials, points to generative qualities that can emerge through altering the tempo of writing. Gunaratnam links this attention to the slow process of research, returning to materials after spaces of thinking and reflection and intervals of time, with these repeated attempts leading both to new insights and ongoing failures in understanding (2013: 159). Therefore, I suggest that as an element of a feminist methodological approach, to conduct vulnerable writing means sometimes it is not always the case of needing more materials because of their incompleteness, but instead it involves working within the textures and material fabrics of what is available. We might need to sit with these complications and contradictions in the constitution and modes of sensory and affective expression, move them backwards and forwards, and to allow these elements and layers to form without attempting to foreclose on the continued emergence of alternatives in all their discomfort.

\footnotetext{
${ }^{2}$ Ayache, A. A Mother's Sacrifice. Gulf News. 27 April 2014. Available at: http://fridaymagazine.ae/features/thebig-story/a-mother-s-sacrifice-1.1324656 [last accessed 19 June 2016].
} 


\section{Slowing and disrupting the tempo}

I take the notion of the unspectacular temporality of precarity from the disruptions offered by Lauren Berlant's (2007) 'slow death' and Rob Nixon's (2011) 'slow violence'. Berlant argues in the context of the notion of slow death, where populations are worn out not by catastrophes, revolutions or resistances but by the slow creeping of the everyday, that 'we need better ways to talk about activity oriented toward the reproduction of ordinary life: the burdens of compelled will that exhaust people...that do not occupy time, decision, or consequentiality in anything like the registers of autonomous self-assertion' (2007: 757). In changing the tempo, Berlant seeks to address how stories of agential, aspirational subjects must also represent the inevitable 'involvement with pain and error, the bad memory and mental lag' that shapes 'indirect routes toward pleasure and survival' (2011: 122). Rather than seeking examples of agency that confirm a constant striving to better ourselves, Berlant suggests we also focus on the means by which we endure life, which, while preventing our immediate deaths, is slowly but surely wearing us out. In a similar way, Nixon identifies elements of slow violence as occurring 'gradually and out of sight, a violence of delayed destruction that is dispersed across time and space, an attritional violence that is typically not viewed as violence at all' (2011: 2). The violence that Nixon articulates struggles to be seen because it is 'incremental and accretive', played out across a 'range of temporal scales' and over the long arc of time that flows through generations (ibid.: 2). Where Berlant's slow death describes the cumulative effect of wearing down populations, Nixon's concept of slow violence addresses the gradual rise in intensity that may be barely registered. The 'long emergency' of slow violence calls attention to the disparate tempos of responses and responsibilities to vulnerable populations. This is witnessed in the insidious workings of certain events whose pace sustains ongoing deferral of action, resulting in violence being enacted through the 'unequal attention given to spectacular and unspectacular time' (ibid.: $3,6)$. The difficulty of visibility for certain subjectivities and bodies living within particular modalities of time is similarly the focus of Mahmood's work on agency, where she addresses the often unseen investments in emotional and physical labour required in the 'agential capacity' that 'is entailed not only in those acts that result in (progressive) change but also those that aim toward continuity, stasis and stability' (2012: 212).

In referring back to Freeman's (2010) work on queer time, an approach to vulnerable writing involves not only slowing forms of time but also a concern for how different temporalities might attach to particular bodies and the 'hidden rhythms' that are normalised through patterns and routine (ibid.: 4). I suggest this method of disruption can involve engaging in a form of temporal syncopation, where, in the rhythmic modes of living, the more visible parts of the narratives are temporally displaced by stressing the lesser beats, the parts of life that do not get heard, or are misheard, ignored or erased in forms of remembering and in modes of telling (ibid.: xii). Temporal syncopation can be used as a methodological approach to displace dominant linear and chronological temporalities of living where actions are connected to causes and effects, and where these relations can predict in advance of time the next beat, or the next action. As a methodological alternative or addition to relational understandings of cause and effect, I suggest that attending to how people move between 
the particularities of temporal scales, conceptualised through considering not only relational but also non-relational elements, has much to contribute to discussions of vulnerable writing within feminist research (Harrison 2007). It might be possible, for example, to see how two registers of violence, gradual erosion and the acute flashpoint, appear to collide, without rushing to attribute intentionality between the two. It might be possible to develop a richer understanding of the temporal discontinuities involved in agency, and how this produces contradictory states, where, for example, Khawli is forced into temporal spaces of waiting that might bring both stasis and uncertainty. Therefore including the question of the nonrelational within a feminist methodological approach might help to consider how the emphasis on finding relations as a method of sense-making and comprehension might be less an epistemological demand than a need we cling to when faced with the vulnerability that occurs from our inability to say 'why this is' or to know how to respond.

\section{Being pricked and wounded}

In vulnerable encounters with what is unfamiliar, where details become part of wider struggles to make sense of the lives of others, I will focus now on how affective trails weaved through encounters extend out beyond the borders of accounts and narratives. These in turn can lead to responses from researchers that shape the conditions, content and production of research. The dynamism of these affective experiences in opening up and closing down receptivity to others suggests the need to address the non-volitional elements of research that come from the singularity of these experiences, leading to the potential for both epistemic and symbolic forms of violence and for ethical responses. To do so I utilise the work of Roland Barthes, who, in the context of photography, refers to the affective extension of media as the 'blind field': the ability to see that which remains off frame (1981). Barthes' was referring to the scaffold or enclosure that is constructed by a photographer, but equally through extending this concept to stories, it can denote the ways we might approach what exceeds the limits of a narrative. Barthes contends that for certain photographs, the contents are held within and 'do not emerge, do not leave: they are anaesthetized and fastened down, like butterflies' (original italics) (ibid.: 56). He calls such an element the studium, whereby participation takes the form of viewing 'recognizable and culturally comprehensible signs' within the singularity of the image, without the viewing causing a disruption or transformation (Gordon 2008: 106). In contrast, the force of the element referred to as the punctum is its relation to the unknown and its power of extension. I suggest it is what can happen when we are moved by something within particular modes of telling. Barthes describes this element in affective terms as an 'accident which pricks me', a sensuous means of wounding that nicks the skin and then burrows in deep below the level of consciousness (ibid.: 27). He contends that acknowledging the punctum is 'in a certain fashion, to give myself up' (original italics) (ibid.: 3 ). Therefore to experience puncturing one must become vulnerable. Its accidental nature is disruptive, it involves a form of surrendering to what is unwilled and unexpected, and in this way might be thought of as receptiveness. What is of particular interest methodologically here is the way the notion of puncturing might help to interrogate epistemological assumptions, and its emergence through attending to the details and particularities within a medium. 
However, again it necessary to consider concerns within particular methods, which in the context of working with the micro layers of stories involves limits to forms of feminist reflexivity. Barthes describes the paradox of the element that pricks, that 'while remaining a "detail," it fills the whole picture' (ibid.: 45). What is critical is that as the viewer, it fills the whole picture for me, the detail floods into my consciousness and it moves me in some affective way. The subject of the narrative or photograph is not transformed from my experience of being wounded; they do not share this feeling and are not necessarily altered as a result. I suggest that the singular nature of the experience of being pricked therefore points to its potential to be self-serving. This expresses a limit of reflexivity, and therefore has implications for feminist methodological approaches, due to its capacity to reinforce the centring of the self within the relation to the other (Mohanty 1984). While reflexivity as a practice involves being accountable for one's situated positioning and the way this impacts the knowledge produced, the status of that knowledge is also called into question through the puncturing. In the context of anthropological research, Kamala Visweswaran contends that self-reflexive texts can 'seek to "tell" how the ethnographer comes to know what she knows' (1994: 84). I suggest that this is different to a reflexive practice that involves hesitations in moving too quickly towards forms of epistemological certitude. As well as 'laying bare the process' of knowledge assembly, I propose that a vulnerable methodology might be more closely positioned with questioning what is known, and what might come from an opening in not knowing (ibid.: 78). The punctum can perform the illusion of knowing through its affective method, by equating wounding with reflexive comprehension. Knowing that one has been wounded, can focus attention on the pricking, suggesting its privileged singularity - that no one else has been moved in a similar way.

Therefore, a concern when engaging with the micro political within a localised analysis is that it can be a means of authorising knowledge (Skeggs 2002: 350). Beverley Skeggs distinguishes between reflexivity as sanctioning the attainment of particular knowledge, and reflexivity as a methodological approach:

...there is a significant difference between being reflexive and accruing reflexivity to oneself through a process of attachment and as a cultural resource to authorize the self and doing reflexivity: building sensitivity into research design and paying attention to practice, power and process (ibid.: 368).

Skeggs argues that being reflexive involves acknowledging that conducting research on others is always 'a privilege, a position of mobility and power, a mobilization of cultural resources' (ibid.: 361). Because of this, I argue there is no necessary equivalence between wounding and ethical responsiveness. Where the punctum may provide some form of enjoyment or pleasure derived from the insights gained, ethical wounds demand in ways that can be painful and relentless. This is because the efficacy of the response relies not on bounded, time-limited attention to the pricking, but on the continued demand to respond. While Barthes focuses on the affective response that comes from the visual sensibility of the photograph, I suggest that both the risk of self-centring and the possibility for ethics might instead reside in the singular nature of being pricked. Rosalyn Diprose addresses directly the necessity and nature of such an experience and positions it as being a disturbance that 
shakes us from our autonomy and questions our relations with others. Diprose asks, 'What experience transports us beyond what constitutes our ways of being and beyond the familiar worlds we inhabit?' (2002: 136). For Diprose, it is the strangeness or alterity of the experience of the other that grounds responsibility and 'inspires sensibility as a condition of thinking' (ibid.: 138). I suggest that it is the connection between being moved affectively, and the response that it provokes that might provide the foundation for an ethical response.

There are temporal conditions to puncturing, where wounds are not always quick, singular and incisive but can also occur by way of slow, deliberate lacerations over time. To illustrate this and its self-referencing potential, what drew my attention initially to Khawli's story were aspects of the narrative that intimated the possibility of something beyond the frame, something I thought that I could see but others could not. However, instead of opening the narrative in ways that made me receptive to further uncertainties and disturbances, I took what I perceived to be the punctum and attempted to explain my response in a way that closed down alternative possibilities and other modes of telling within the narrative. Therefore, I suggest that being pricked has the potential open up, but also close down responses. In working with an account of Khawli's self-immolation, the moment of being wounded occurred when I read the a news article that documented Khawli saying from her hospital bed, 'They burned my heart before they burned my body. ${ }^{3}$ This statement disturbed me due to the pain it communicated, the visceral emotional image it invoked, and its illogical premise that unsettled my understanding of the self within self-immolation: how could someone burn Khawli first, and is it even physically possible to burn from the inside out? It was Khawli's act of speaking after her self-immolation that I ascribed with a certain reflexive and authentic form of knowing. I realised that I had give credence to the temporal as a conditioning agent of knowledge, in this case its influence in the power and uptake of meaning conveyed through speech being performed at a certain moment in time (Austin 1962). Because of this, I was closing down inquiry into other means and expressions of communication and utterances that might occur during experiences of suffering. I had assumed that certain acts, emotions and events that happen to people remain expressible, and that sensorial and affective understandings and responses to trauma can be conveyed by words. I assumed that words might contain more meaning than other forms of expression, and where these words are temporally located might serve to expose particular meanings that would otherwise be absent.

And so with this vulnerability to my own thinking exposed, I experienced being punctured by the sudden dismantling of boundaries to Khawli's story I realised I had constructed for my own emotional comfort. I assumed that a lack of details about Khawli's progress and her presence in videos and photographs in a hospital bed being attended to by medical staff indicated that Khawli had survived her burns. When I searched online for what had happened to Khawli in the days after her self-immolation, I could not find any information detailing her life after 27 April 2014. I contacted a journalist who had written the most recent article I could find and had initiated a public appeal to raise funds for Khawli's

\footnotetext{
${ }^{3}$ Damon, A. and Razek, R. Syria Refugee's Desperate Act: 'They Burned My Heart Before They Burned My Body'. CNN, 3 April 2014. Available at: http://edition.cnn.com/2014/04/03/world/meast/syria-refugee-lebanondamon-razek/ [last accessed 19 June 2016].
} 
medical costs. I asked the journalist for news of Khawli and of what happened to the funds that were raised. I received an email a day later that said the journalist was sorry to inform me that Khawli had passed away shortly after her article went to print. I realised that Khawli had not been alive throughout the duration of my time spent with her story. She had passed away months prior to me watching her speak on video. I remembered from a media article that Khawli's husband Ahmad had reassured their children soon after Khawli's selfimmolation that their mother had survived. This news came in the form of a strong emotional and physical response that forced me to physically get up and get out of the space that I was in, to walk and somehow try and make sense of what I was feeling. My response also felt disingenuous, a sensation invoked from a relationship that I did not have. It made me quite uncertain as to what I was experiencing, but it did feel like a form of loss, that someone I knew had died. This is the expansive power of being pricked, where receptivity to the details, to the complicated suffering and continued surviving of another person, may not come to form any certainty about what has taken place or be commensurable to other forms of experience, but what it can do is to help to keep the dialogue open.

The dynamism of these forms of wounding exposes the vulnerability of the story telling process to the deceptive comforts of completeness, and reminds that life both continues and ceases to exist beyond the telling. To engage with the instability, I suggest that there must be a certain acceptance to the puncturing that occurs. Therefore these moments of pricking, of being moved, may contain the emergence of an ethical response within modes of feminist research. What I find to be crucial in relation to methodological practices of narrating other people's stories is how Barthes contends that while the punctum comes to define what we add to a story, it is only an addition that we make: 'It is what I add to the photograph and what is nonetheless already there' (original italics) (1981: 55). It disrupts the power of the temporal within sovereign forms of knowledge making. This displaces the notion of cognition as being prior to the encounter; that cognition in the form of understanding is required in order to be responsive as a researcher. In referring to the example above, the particular details that caused a disturbance were already present, they are part of Khawli's life: the effect of the punctum in me did not disclose anything that Khawli did not already live with.

As an implication for the practice of reflexivity within feminist methodologies, in attending to the temporalities of research I suggest that vulnerable and invulnerable research methods may coexist through the stages of a project, where invulnerability exists as a form of protection that is at times necessary, creating spatial and affective forms of distance to the subjects of research. This is where the specificity of the puncture mark is important. Distance can be maintained by reversing the process of wounding: puncturing the object of study by attributing forms of agency or intentionality that are willed by the researcher while protecting the self against being pricked whether intentionally or at times unintentionally. What may occur is continual movement between forms of vulnerable and invulnerable methods according to context and need, and where invulnerability as protection encompasses the potential to make way for reflexive, localised practices that open up space for vulnerable responses. 


\section{Conclusions}

What are the consequences of acknowledging forms of vulnerable wounding in research? In their consideration of responses to the material production of research, Mariam Fraser and Nirmal Puwar draw attention to how 'sensory, emotional and affective relations are central to the ways in which researchers engage with, produce, understand and translate what becomes 'research" (2008: 2). Fraser and Puwar contend that there is much to be learned about 'how we creatively carry the smells, textures, pains, desires, sounds and the visual store of memories of the research encounter with us, from the points of collection, to analyses and public presentation' (ibid.:2). One implication for vulnerable methods is the contested forms of intimacy that are produced in the labour of research, and how the sensory and affective experiences of such labour are often left out of discussions of methodology (ibid.: 2). Is there a place for communicating the intangible qualities of the emotional feelings that I experienced in working with the story of Khawli? In what way might that re-centre myself within the narrative? These are questions that continue to have a place in discussions of feminist methods, and especially in spaces where the distance of transnational concerns complicates forms of intimacy and an idea of closeness to those we write about. Sara Ahmed (2014 [2004]) argues that in remaining with the distance between the self and another person, distance can suggest the very ethics of response. It could involve 'being open to being affected by that which one cannot know or feel' (ibid.: 30). In connecting this to methodological practices, to be attuned to sensitivities of a narrative and to attempt to reduce forms of violence is not to suggest that this means the story must become intelligible. As a form of vulnerable writing it might involve what Berlant refers to as the 'pain of paying attention' that comes from admitting to our 'surprising attachments' to another person (2011: 123, 122).

In this article I have argued for the space to consider what might be generative of vulnerable forms of writing and how this might occur through working at the intersections of feminist, postcolonial and queer methodological practices and approaches. In disrupting the ways knowledge is produced by questioning what is known, and how and within the time that it comes to be understood, I suggest that a vulnerable methodology can help to extend a feminist reflexive practice by calling attention to the temporal conditions of affective puncturing and the risks of wounding being equated with reflexive comprehension. Therefore, instead of knowing as a 'means of knowing what to do', the unsettled disturbance of not knowing that occurs through recognising the necessary construction of spatial and temporal boundaries to narratives becomes integral to the research engagement (Weigman 2014: 7). A vulnerable method does not attempt to resolve discomfort immediately through problem solving, or by forms of sense-making that utilise particular relational elements of cause and effect. Instead, what is at the heart of vulnerable methods and vulnerable writing are ongoing questions about what unsettles, about relations to the unfamiliar and strange, and about the erasure of the complexities of subjectivity when individuals and bodies and their actions do not fit or adhere to coherent themes of knowledge. This unsettled uncertainty of the research process, rather than foreclosing on further understandings, provides space for new forms of unknowing, and continued 
attempts at understanding the stories of others.

\section{Acknowledgments}

I extend my sincere thanks to Yasmin Gunaratnam and Carolyn Pedwell for their continued support in helping me to develop the themes that have informed this article. Thank you to the anonymous reviewers for their comments.

\section{References}

Ahmadi, A., Ranjbaran, H., Azadbakht, M,. Heidari Gorji, M., Heidari Gorji, A. 2014. Survey of characteristics of self-Immolation in northern Iran. Annals of Medical and Science Research, $4(3)$, pp.228-232.

Ahmed, S., 2014. The Cultural Politics of Emotion. Edinburgh: Edinburgh University Press.

Ahmed, S., 2000. Strange Encounters: Embodied Others in Post-Coloniality. London: Routledge.

Austin, J.L. 1962. How To Do Things With Words: The William James Lectures Delivered At Harvard University in 1955. Oxford: Clarendon Press.

N. Aziz, 2011. What self-immolation means to Afghan women. Peace Review, 23(1), pp.4551.

Barthes, R., 1981. Camera Lucida: Reflections On Photography. Trans. Richard Howard. New York: Hill and Wang.

Behar, R., 1996. The Vulnerable Observer: Anthropology That Breaks Your Heart. Boston: Beacon Press.

Berlant, L., 2011. Cruel Optimism. Durham: Duke University Press.

Berlant, L., 2007. Slow death (sovereignty, obesity, lateral agency). Critical Inquiry, 33, pp.754-780.

Butler, J., 2015. Notes Towards a Performative Theory of Assembly. Cambridge, Massachusetts: Harvard University Press.

Butler, J., 2015b. Vulnerability and Resistance Revisited. Public Lecture delivered at Trinity College Dublin.

Butler, J., 2012. Parting Ways: Jewishness and the Critique of Zionism. New York: Columbia University Press. 
Butler, J., 2010. Precarious Life: The Powers of Mourning and Violence. London: Verso.

Butler, J., 2004. Frames of War: When is Life Grievable? London: Verso.

Derrida, J., 2000. Of Hospitality. Trans. R. Bowlby. Stanford: Stanford University Press.

Dikeç, M., Clark, N., Barnett, C., 2009. Extending hospitality: giving space, taking time. Paragraph: A Journal of Modern Critical Theory, 32(1) Edinburgh: Edinburgh University Press, pp. 1-14.

Fraser, M., Puwar, N., 2008. Introduction: intimacy in research. History of the Human Sciences, 21(4), pp.1-16.

Freeman, E., 2010. Time Binds: Queer Temporalities, Queer Histories. Durham: Duke University Press.

Gordon, A., 2008. Ghostly Matters: Haunting and the Sociological Imagination. Minneapolis: University of Minnesota Press.

Gunaratnam, Y., 2013. Death and the Migrant. London: Bloomsbury Academic.

Gunaratnam, Y., 2011. Cultural vulnerability: A narrative approach to intercultural care. Qualitative Social Work, 12(2), pp.104-118.

Gunaratnam, Y., 2008. From competence to vulnerability: care, ethics, and elders from racialized minorities. Mortality: Promoting the interdisciplinary study of death and dying, 13(1), pp.24-41.

Halberstam, J., 2011. The Queer Art of Failure. Durham and London: Duke University Press.

Harrison, P., 2007. "How shall I say it...?" Relating the nonrelational. Environment and Planning A, 39, pp. 590-608.

Lather, P. 2001. Working the Ruins of Feminist Ethnography. Signs, 27 (1), pp.199-227.

Love, H., 2007. Feeling Backwards: Loss and the Politics of Queer History. Cambridge MA: Harvard University Press.

Mahmood, S., 2011. Politics of Piety: The Islamic Revival and the Feminist Subject. Princeton: Princeton University Press.

Mani, L., 1998. Contentious Traditions: The Debate On Sati In Colonial India. Berkeley and Los Angeles: University of California Press.

Mohanty, C., 2003. “Under Western Eyes" Revisited: Feminist Solidarity through 
Anticapitalist Struggles. Signs, 28(2), pp.499-535.

Mohanty, C., 1984. Under Western Eyes: Feminist Scholarship and Colonial Discourses. boundary, 12(3), pp.333-358.

Muñoz, J,. 2009. Cruising Utopia: The Then and There of Queer Futurity. New York: New York University Press.

Nixon, R., 2011. Slow Violence and the Environmentalism of the Poor. Cambridge: Harvard University Press.

Pedwell, C., 2014. Affective Relations: The Transnational Politics of Empathy. Basingstoke: Palgrave Macmillan.

Povinelli, E., 2011. Economies of Abandonment: Social Belonging and Endurance in Late Liberalism. Durham and London: Duke University Press.

Sedgwick, E., 2003. Touching Feeling Affect, Pedagogy, Performativity. Durham: Duke University Press.

Smith, L. T., 1999. Decolonizing Methodologies: Research and Indigenous People. London: Zed Books.

Wiegman, R., 2014. The Times We're In: Queer Feminist Criticism and the Reparative 'Turn'. Feminist Theory, 15(1), pp.4-25.

Spivak, G., 1993. Outside the Teaching Machine. New York: Routledge. 